\title{
The effects of operating parameters on spiramycin removal by nanofiltration membrane
}

\author{
Changwei Zhao, Weihong Fan, Tao Wang, Deyin Hou and Zhaokun Luan
}

\begin{abstract}
Spiramycin removal from wastewater using four nanofiltration (NF) membranes (NF270, NF90, ESNA1-K1 and ESNA1-LF2-LD) was studied. The effects of operating pressure, feed temperature, feed concentration, cation and anion ions on the permeate flux rate and spiramycin rejection were investigated. The results show that increasing operating pressure resulted in the increase of both permeate flux and spiramycin rejection. The flux rate increased almost linearly with temperature, while the spiramycin rejection decreased. The permeate flux rate declined relatively with increasing feed concentration of spiramycin for NF270 and ESNA1-LF2-LD membranes compared with NF90 and ESNA1-K membranes. The presence of cations reduced spiramycin rejection, with the strength of influence for the NF270 NF membrane following the order $\mathrm{Mg}^{2+}>\mathrm{Ca}^{2+}>\mathrm{K}^{+}$. The presence of anions also resulted in decreased spiramycin rejection, the strength of the effect following the order $\mathrm{NO}_{3}^{-}>\mathrm{Cl}^{-}>\mathrm{SO}_{4}^{2-}$ for the NF270 membrane.
\end{abstract}

Key words | ion effect, nanofiltration, spiramycin removal, wastewater

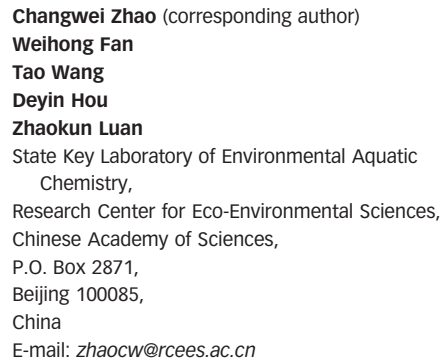

\section{INTRODUCTION}

The ubiquitous presence of pharmaceuticals including antibiotics as a growing contributor of trace contaminants, which have been making significant contributions to the healthcare of human beings over the past number of decades (Homem \& Santos 20II; Sun et al. 20II; Heo et al. 20I2), may cause severe long-term problems due their high persistence and biological activity in the environment (Koyuncu et al. 2008). With the wide use and abuse of antibiotics, their content in the aquatic environment has risen and consequently increased in wastewater, water reuse applications, tap water and drinking water (Kim et al. 2007; Kosutic et al. 2007; Homem \& Santos 20II). Previous studies proved a link between environmental exposure and deteriorating trends in human health. Both original forms and respective metabolites would result in detrimental ecosystems and significant adverse health effects (Lee et al. 20II; Chon et al. 2012). Before antibiotics release into aquatic environments, the inefficient removal from discharge streams may both contaminate drinking water security and promote the growth of antibioticresistant bacteria with severe ecological issues (Sun et al. 20II). These findings clearly demonstrate it is important to develop effective technology to remove pharmaceuticals for human health (Kinney et al. 2006; Batt et al. 2007).
A number of chemical and physical methodologies, such as chemical oxidation, adsorption, liquid extraction and membrane techniques have been employed for pharmaceutical removal. Amongst these, membrane processes have emerged as a promising new route for high quality water purification, with many advantages, including there being no requirement for the addition of chemical substances, ease of scale up, separation in the continuous mode and the possibility to readily combine membrane processes with other unit processes (Paul \& Douglas 2000; Figoli et al. 2010; Xu et al. 2012). Of the available membrane technologies applicable as clean-up methods, nanofiltration (NF) is efficiently able to remove antibiotics from water owing to the small size of the membrane pores. Because of its advantages, such as low operating pressure and high retention of multivalent anions, it has generated worldwide interest, and has been used to remove various pollutants during water treatment (Zhang et al. 2003; Braeken et al. 2004; Koyuncu et al. 2008; Mo et al. 2008). Recent developments in membrane technology have enabled NF to be a potential technology for pharmaceutical removal (Shi et al. 2006; Koyuncu et al. 2008).

Dolar et al. (20II) showed that low concentration of calcium ions $(6 \mathrm{mg} / \mathrm{L})$ could not have a major impact on 
rejection of veterinary pharmaceuticals by NF. Shirra et al. (20II) reported the increase of $\mathrm{NaCl}$ concentration in the solution; the rejection of diatrizoate remained practically unchanged, but the rejection of carbamazepine had a slightly lower decrease by NF270. Zazouli et al. 2009 showed that changes of ionic content led to increase for SR3 or decrease for SR2 of cephalexin rejection, depending on the membrane used. These are not consistent with the results of ion effects on pharmaceutical rejection. Furthermore, previous reports of ions on pharmaceutical removal by NF were mainly focused on the effect of one ion on pharmaceutical removal performance. Spiramycin is a medium-spectrum, macrolide antibiotic widely used in the treatment of respiratory infections. Since the drug enters the oral cavity through gingival crevicular fluid and saliva, spiramycin persists for extended periods at potentially therapeutic concentrations (Rams et al. 20II). It may be released directly to the environment with waste. In addition, passing through wastewater treatment plants spiramycin may enter aquatic environments and result in detrimental ecosystems and significant adverse health effects. It is of concern in the environment how to remove spiramycin from wastewater. In previous relevant works on pharmaceuticals removal, little research was about spiramycin by the NF membrane. As spiramycin is one of the main antibiotics, studying its separation performance by NF is also necessary. Also it is necessary to investigate the difference of different cation and anion feed streams on spiramycin removal performance. Another, efficient spiramycin removal by NF also depends on many factors, including membrane properties, operating pressure, feed temperature, feed concentration and the presence of co-existing ions (including different cations and anions). Further investigations into these parameters are of interest for the development of spiramycin removal strategies using NF processes.

In the present study, spiramycin was chosen as a pharmaceutical and four different commercial NF membranes (NF270, NF90, ESNA1-K1 and ESNA1-LF2LD) were chosen to remove spiramycin under a variety of operating conditions. The novel additional data obtained on the removal efficiency and rejection of various membranes is expected to contribute to an improved understanding of spiramycin rejection.

\section{METHODS}

\section{Materials}

Spiramycin (purchased from Melone Pharmaceutical Co., Ltd, China) and its main chemical properties $\mathrm{MW}=$ 843.05, $\log K_{\text {ow }}$ is $2.49 \pm 0.82$ (Sorensen 2000). The cations $\left(\mathrm{CaCl}_{2}, \mathrm{MgCl}_{2}\right.$ and $\left.\mathrm{KCl}\right)$ and anions $\left(\mathrm{NaCl}, \mathrm{NaNO}_{3}\right.$ and $\mathrm{Na}_{2} \mathrm{SO}_{4}$ ) ions and other chemicals (purchased from Sinopharm Chemical Reagent Co., Ltd, China) were all of analytical grade. According to the determination of antibiotic production wastewater from a pharmaceutical manufacturing factory in Wuxi of China (Bai 20I2; Bai et al. 2012), in this manuscript simulated wastewater was used and prepared as follows: different amounts of spiramycin were dissolved in deionized water, then various cations calcium (as $\mathrm{CaCl}_{2}$ ), magnesium (as $\mathrm{MgCl}_{2}$ ), potassium (as $\mathrm{KCl}$ ), anions chloride (as $\mathrm{NaCl}$ ), nitrate (as $\mathrm{NaNO}_{3}$ ), sulfuric acid (as $\mathrm{Na}_{2} \mathrm{SO}_{4}$ ) at approximately the concentration range from actual wastewater were added into spiramycin solution and mixed to prepare simulated wastewater. These cations and anions were selected because they were detected in actual wastewater. In all the experiments, solution $\mathrm{pH}$ was adjusted to $\mathrm{pH}=7$. Four types of commercial flat NF membranes, NF270, NF90, ESNA1-K1 and ESNA1-LF2-LD, were selected for the NF experiments. Table 1 shows the general characteristics of the four membranes ( $\mathrm{Yu}$ et al. 20I3).

Table 1 | General characteristics of the nanofiltration membranes

\begin{tabular}{llll} 
Membrane & NF270 & NF90 & ESNA-1-K1 \\
\hline Manufacturer & Dow-Flimtec & Dow-Flimtec & Hydranautics \\
Material & Polypiperazine-based & Composite polyamide & Aromatic polyamide \\
MWCO & 200 & 100 & $200-300$ \\
MgSO $_{4}$ rejection $(\%)$ & 97 & 94.6 & 97 \\
Surface charge & Negative & Negative & Negative \\
Zeta potential & $-21.6^{\mathrm{a}}$ & $-24.9^{\mathrm{a}}$ & $-17.5^{\mathrm{b}}$ \\
\hline
\end{tabular}

abtained from Plakas \& Karabelas (2008).

bobtained from Nanda et al. (2008). 


\section{Nanofiltration process}

A diagram of the NF experimental setup is shown in Figure 1. The NF membrane module was an annular chamber made of stainless steel, in which a membrane supported by porous sintered steel was mounted. The effective area of the membrane was $27.05 \mathrm{~cm}^{2}$. Each new membrane was initially operated for $30 \mathrm{~min}$ at $1.0 \mathrm{MPa}$ before commencing the actual separation study.

The effect of a range of operating conditions, including operating pressure, temperature, spiramycin feed concentration, and cationic and anionic ions, on spiramycin rejection was investigated in experimental trials, in which one of the variables was varied, whilst the others were kept constant.

Water flux rate was obtained by measuring the volume of permeate that penetrated the unit area membrane per unit time, defined as:

$J=V / A t$

where $V$ is the total volume of pure permeate during the experiment, $A$ represents the membrane area and $t$ denotes the operation time.

The rejection $R$, was determined in each experiment and defined as:

$R=1-\frac{C_{\mathrm{p}}}{C_{\mathrm{f}}}$

where $C_{\mathrm{p}}$ and $C_{\mathrm{f}}$ are the permeate and feed concentrations, respectively.

\section{Sample analyses}

The spiramycin concentration was measured colorimetrically according to standard methods using UV-Vis

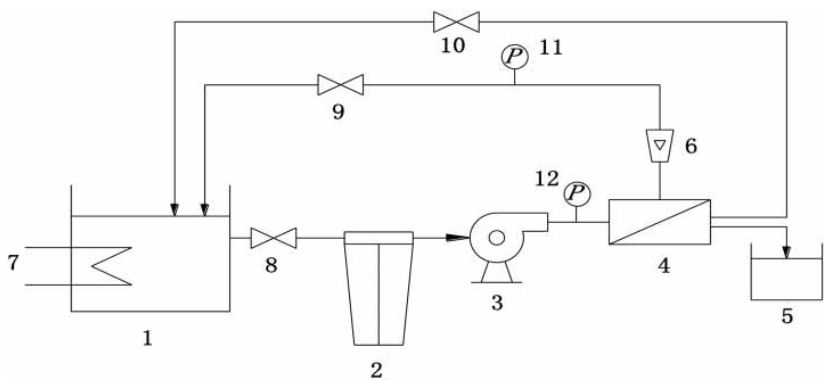

Figure 1 | Diagram of the experimental setup. 1. Feed tank, 2. precision filter, 3. pump, 4 membrane module, 5. permeate, 6. flowmeter, 7. heater, 8, 9 and 10. valve, 11. and 12. pressure gauge. spectrophotometry (DR5000, Hach, USA) (China's environmental protection administration 2002). Each group of experiments was carried out in duplicate to determine reproducibility and mean values considered.

\section{RESULTS AND DISCUSSION}

\section{Effect of operating pressure on membrane performance}

Because NF is a pressure-driven physical process, operating pressure is an important factor in determining membrane performance. To examine the influence of operating pressure on spiramycin removal, experiments were performed at $0.4,0.6,0.8,1.0$ and $1.2 \mathrm{MPa}$ with NF270, NF90, ESNA1-K1 and ESNA1-LF2-LD membranes at a spiramycin feed concentration of $65 \mathrm{mg} / \mathrm{L}$, at $30{ }^{\circ} \mathrm{C}$ and $3 \mathrm{~L}$ $\min ^{-1}$ feed flowrate. Results are shown in Figures 2 and 3.

As shown in Figure 2, the permeate flux rate increased linearly in proportion to operating pressure, consistent with previous reports (Bhanushali et al. 200I; Robinson et al. 2004). From Figure 3 we can see that spiramycin rejection increased with increasing operating pressure. It can also be seen that spiramycin rejection by the four membranes was higher than $92 \%$ over the pressure range investigated.

\section{Effect of feed temperature on membrane performance}

To investigate the influence of feed temperature on the removal of spiramycin, experiments were performed over a range of temperatures with the four membranes at a

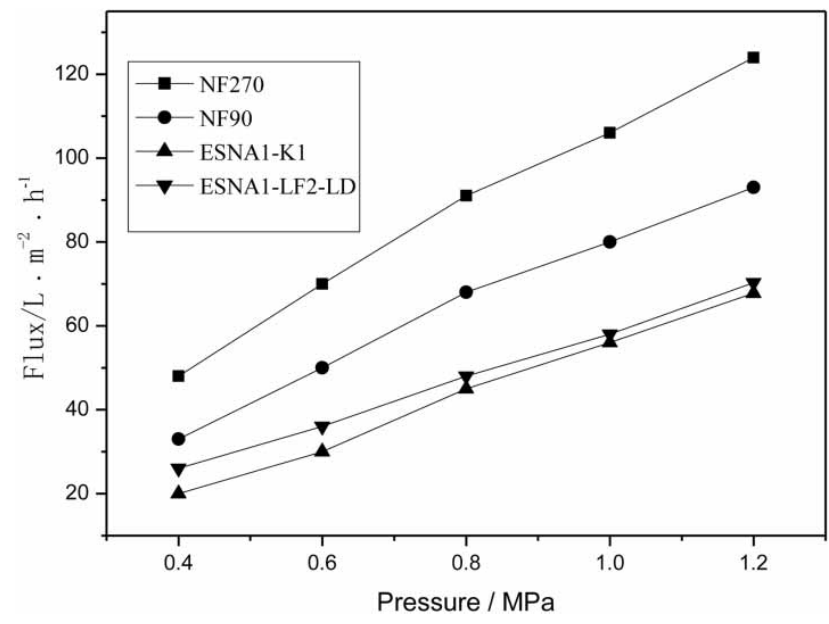

Figure 2 Influence of the pressure on flux rate (feed concentration $65 \mathrm{mg} \mathrm{L}^{-1}$; feed temperature $30{ }^{\circ} \mathrm{C}$; flowrate $3 \mathrm{~L} \mathrm{~min}^{-1}$ ). 


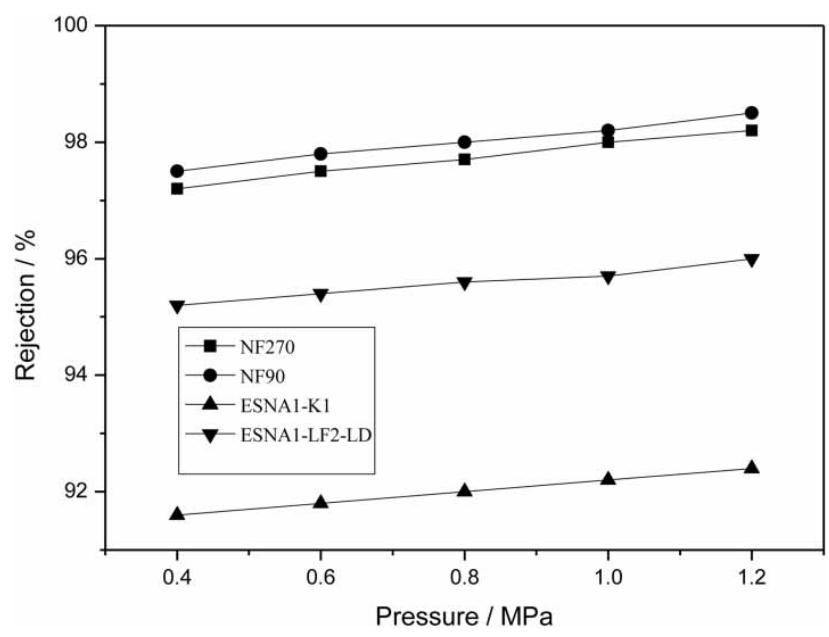

Figure 3 | Influence of the pressure on spiramycin rejection (feed concentration: $65 \mathrm{mg}$ $\mathrm{L}^{-1}$; feed temperature $30^{\circ} \mathrm{C}$; flowrate $3 \mathrm{~L} \min ^{-1}$ ).

spiramycin feed concentration of $65 \mathrm{mg} \mathrm{L}^{-1}$, at $0.6 \mathrm{MPa}$ and $3 \mathrm{~L} \mathrm{~min}^{-1}$ flowrate. Results are shown in Figures 4 and 5.

Flux was established according to the irreversible thermodynamic model combined with the film model (Park et al. 2005; Park \& Cho 2008) as follows:

$J C-D \frac{\mathrm{d} c}{\mathrm{~d} x}=J C_{\mathrm{p}}$

By integration of Equation (3) a simple model was provided as follows:

$J=k \ln \left(\frac{C_{\mathrm{m}}-C_{\mathrm{p}}}{C_{\mathrm{b}}-C_{\mathrm{p}}}\right)$

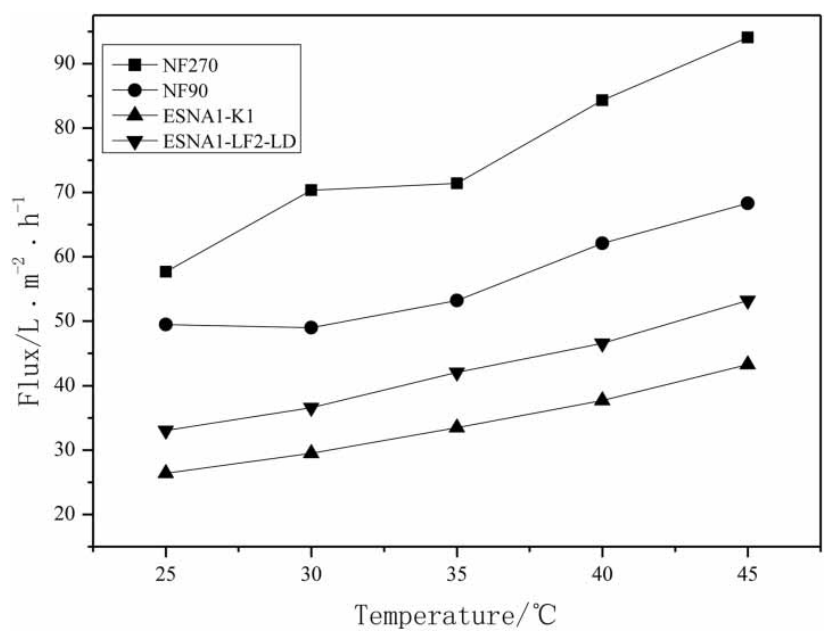

Figure $4 \mid$ Influence of feed temperature on flux rate (pressure $0.6 \mathrm{MPa}$; feed concentration $65 \mathrm{mg} \mathrm{L}^{-1}$; flowrate $3 \mathrm{~L} \mathrm{~min}^{-1}$ ).

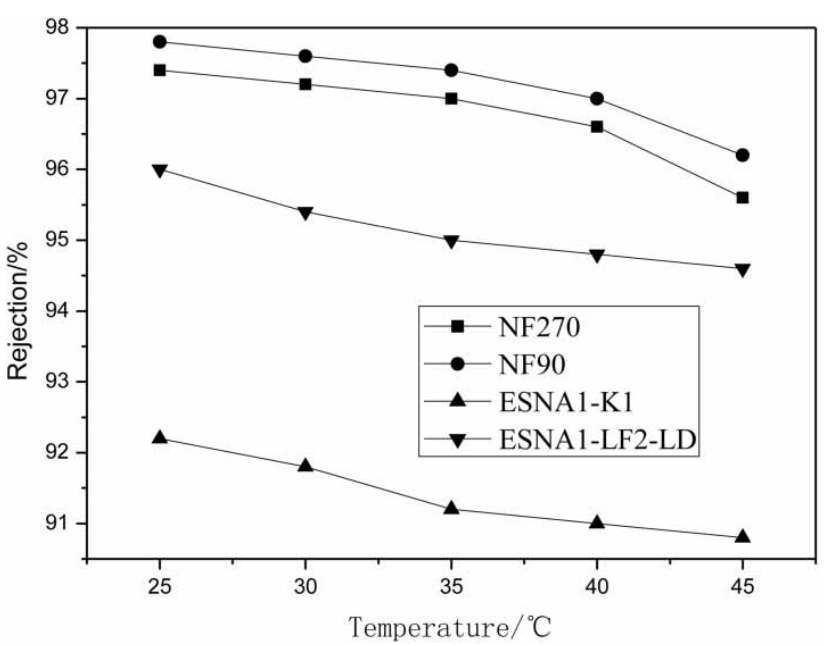

Figure 5 | Influence of feed temperature on spiramycin rejection (pressure $0.6 \mathrm{MPa}$; feed concentration $65 \mathrm{mg} \mathrm{L}^{-1}$; flowrate $3 \mathrm{~L} \mathrm{~min}^{-1}$ ).

where $J$ is the flux, $D$ the diffusion coefficient, $k$ the mass transfer coefficient, $C_{\mathrm{b}}$ the bulk concentration, $C_{\mathrm{m}}$ the membrane surface concentration, $C_{\mathrm{p}}$ the permeate concentration, respectively.

It was well known that the temperature played a very important role in the diffusion process. In general, the temperature dependence of the diffusion coefficient is given by the Arrhenius equation as follows:

$D=D_{0} \exp ^{-\Delta E \mathrm{D} / R T}$

where $D_{0}$ is the pre-exponential factor of the diffusion process independent from the temperature, $\Delta E_{\mathrm{D}}$ the activation energy for a diffusing species in a given polymer matrix to escape from its present surroundings and move into an adjacent different surrounding. $R$ is the gas constant, $T$ absolute temperature.

As shown in Figure 4 it can be seen that flux increased with temperature, this is consistent with the diffusion coefficient increasing with the increase of feed temperature.

From Figure 5 we can see that the spiramycin rejection by the four membranes decreased with feed temperature increase. The reason may be that the effective pore radius increases when the feed temperature increases, which reduces the effect of the intercept according to the sieving mechanism of NF. Another, higher temperature increases the diffusivity of spiramycin as the solutes. Since transport of solutes through pores is mainly diffusive, the increase in diffusivity of spiramycin results in a decrease in rejection (Sorin et al. 2005). 


\section{Effect of feed concentration on membrane performance}

There is often a concentration polarization problem in membrane separation processes at high solute concentrations (Bouchoux et al. 2005). To determine whether concentration polarization occurred in this process, experiments were performed at a range of feed concentrations. Figures 6 and 7 show the flux rate and rejection of spiramycin as a function of feed concentration for the four membranes at $30^{\circ} \mathrm{C}$, $0.6 \mathrm{MPa}$ and $3 \mathrm{~L} \mathrm{~min}{ }^{-1}$ flowrate.

As shown in Figure 6, for four membranes, the permeate flux declined a little with increasing feed concentration. The explanation for this trend is that it might be due to the

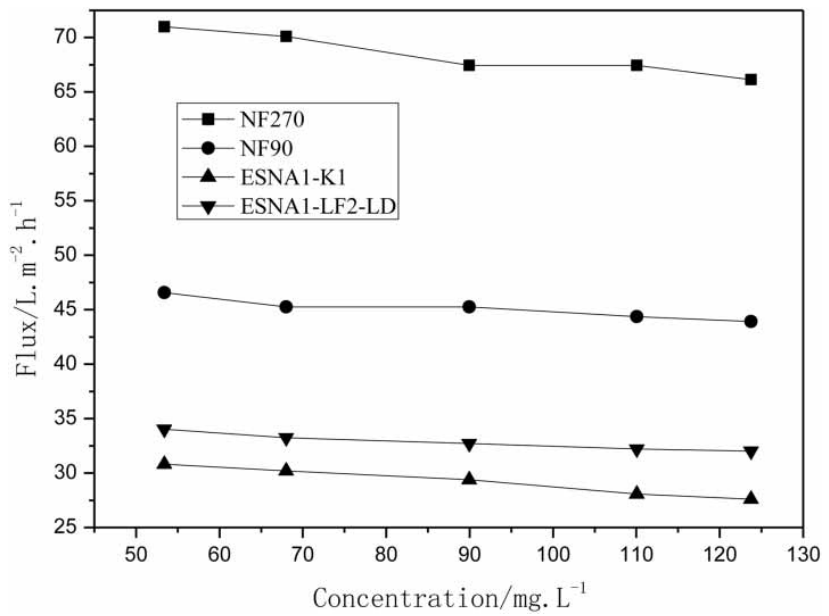

Figure 6 | Effect of feed concentration on flux rate (pressure 0.6 MPa; feed temperature $30{ }^{\circ} \mathrm{C}$; flowrate $3 \mathrm{~L} \mathrm{~min}^{-1}$ ).

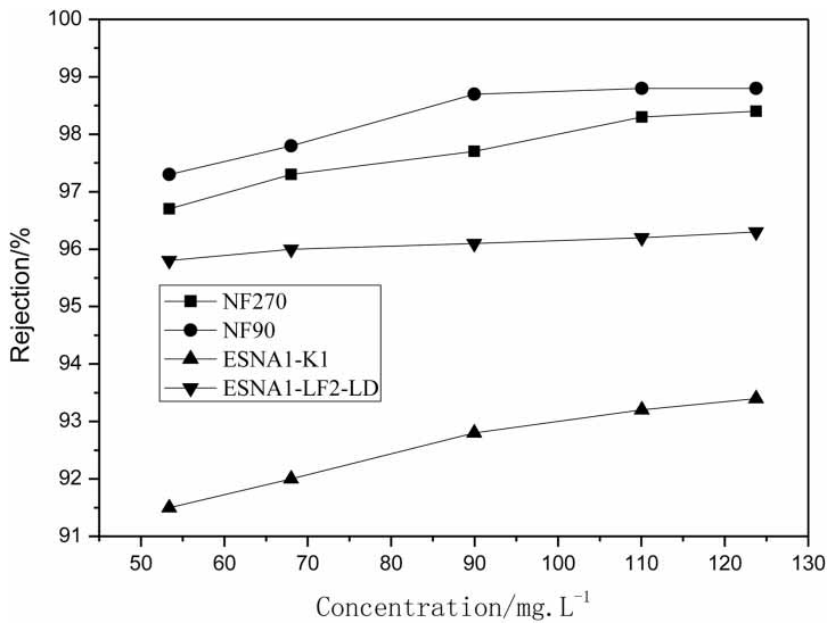

Figure 7 Effect of feed concentration on spiramycin rejection (pressure $0.6 \mathrm{MPa}$; feed temperature $30{ }^{\circ} \mathrm{C}$; flowrate $3 \mathrm{~L} \mathrm{~min}^{-1}$ ). decrease of the effective membrane pore size owing to adsorption or deposition of spiramycin on the membrane surface with the increase of feed concentration. Another reason might be the increase in osmotic pressure owing to the increase of mass transfer resistance (Rashdi et al. 2013). From Figure 7 we can see that spiramycin rejection by the four membranes exceeded 92\% over the range of feed concentrations investigated. Spiramycin rejection increased with spiramycin feed concentration for the four membranes. The reason for this may be that a higher mass transfer resistance caused a higher feed concentration based on cake resistance model (Listiarini et al. 2009), and pore size decreased. Consequently, the sieving effect would increase, which results in rejection increase.

\section{Effect of cations on spiramycin removal}

Various inorganic, cationic ions co-exist with antibiotics in wastewater and the presence of these substances can interfere with spiramycin removal. Therefore, it is important to determine the rejection characteristics of cationic species in a mixed salt solution using the NF process. $\mathrm{CaCl}_{2}$, $\mathrm{MgCl}_{2}$ and $\mathrm{KCl}$ were selected to assess the effects of cations on spiramycin removal. Experiments were carried out by adding each cation at various concentrations into spiramycin-dosed water with the NF270 membrane at a feed spiramycin concentration of $65 \mathrm{mg} \mathrm{L}^{-1}$ at $0.6 \mathrm{MPa}, 30{ }^{\circ} \mathrm{C}$ and $3 \mathrm{~L} \mathrm{~min}^{-1}$ flowrate. Results are shown in Figure 8.

The experimental results show that the presence of cations caused a decrease in spiramycin rejection, with higher ion concentrations causing a greater decrease in

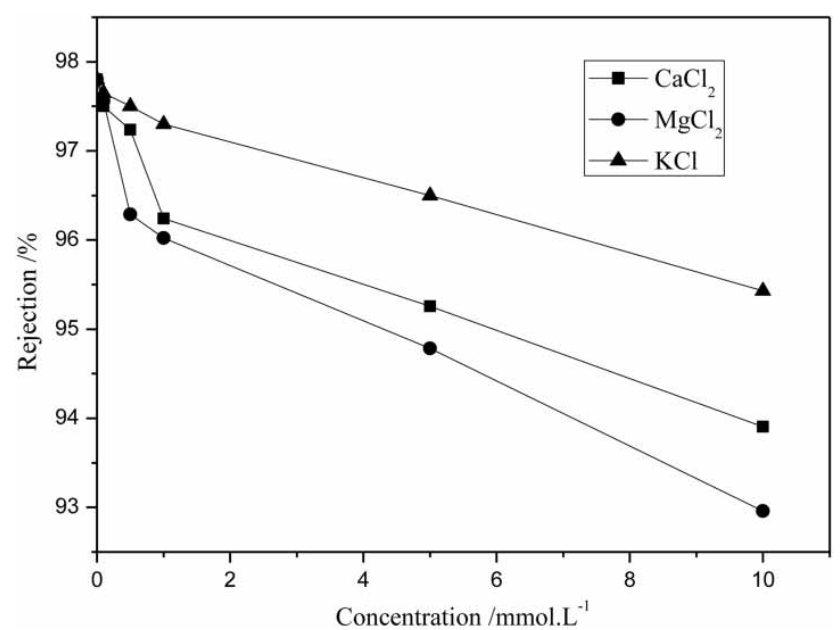

Figure 8 | Effect of the concentration and varieties of cations on spiramycin rejection (NF270 membrane, feed concentration $65 \mathrm{mg} \mathrm{L}^{-1}$; pressure $0.6 \mathrm{MPa}$; feed temperature $30^{\circ} \mathrm{C}$; flowrate $3 \mathrm{~L} \mathrm{~min}^{-1}$ ). 
rejection. Two hypotheses can explain this phenomenon. One explanation is a pore swelling. Adding a salt in solution would result in an increase of the membrane charge density, which induces a greater counter-ions concentration in the electrical double-layer at the pore surface. Another, direct interactions between the solutes can be used to describe the decrease of rejection. In a mixed-solute solution of spiramycin and a salt, according to the Hofmeister effect (Kunz et al. 2004) water will indeed preferentially solvate the salt to the detriment of spiramycin. Therefore spiramycin was less hydrated, and permeated more freely through the membrane with a lower apparent volume than in the absence of a salt. This 'salting-out' effect is related to the salt concentration and becomes stronger with the concentration increase (Bouchoux et al. 2005; Geens et al. 2005). In addition, high concentration of ion can reduce the flux due to higher osmotic pressure and it can reduce removal efficiency.

As shown in Figure 8, the influence of the cations on spiramycin rejection for the NF270 NF membrane followed the sequence $\mathrm{Mg}^{2+}>\mathrm{Ca}^{2+}>\mathrm{K}^{+}$. A higher viscosity coefficient for the ion caused a stronger hydration effect, which more easily dehydrated the spiramycin molecule, reducing the rejection of spiramycin. From Table 2 we can see that the order of the cation size effect was $\mathrm{Mg}^{2+}>\mathrm{Ca}^{2+}>\mathrm{K}^{+}$ and the radius size order is $r_{\mathrm{s}}\left(\mathrm{Mg}^{2-+}\right)>r_{\mathrm{s}}\left(\mathrm{Ca}^{2+}\right)>r_{\mathrm{s}}\left(\mathrm{K}^{+}\right)$. Thus, it seems that both the Hofmeister series and the streaming effect of the ions was consistent with the order of the influence on rejection.

\section{Effect of anions on spiramycin removal}

Similarly, various anionic species exist in antibiotic wastewater and their presence can interfere with spiramycin removal. Therefore, it is important to identify the rejection characteristics of anions in a mixed salt solution using the $\mathrm{NF}$ process. $\mathrm{NaCl}, \mathrm{NaNO}_{3}$ and $\mathrm{Na}_{2} \mathrm{SO}_{4}$ were selected to assess the effects of anions on spiramycin removal.

\begin{tabular}{lcc} 
Table 2 | Viscosity coefficient and Stokes radii of ions & \\
Ion & Viscosity coefficient $\boldsymbol{B}_{\boldsymbol{\eta}}$ & Radii (nm) \\
\hline $\mathrm{K}^{+}$ & -0.009 & 0.124 \\
$\mathrm{Mg}^{2+}$ & 0.385 & 0.345 \\
$\mathrm{Ca}^{2+}$ & 0.284 & 0.307 \\
$\mathrm{Cl}^{-}$ & -0.005 & 0.120 \\
$\mathrm{NO}_{3}^{-}$ & -0.043 & 0.128 \\
$\mathrm{SO}_{4}^{2-}$ & 0.206 & 0.299 \\
\hline
\end{tabular}

Experiments were carried out by adding each anionic ion at a range of concentrations into spiramycin water with the NF270 membrane at a feed spiramycin concentration of $65 \mathrm{mg} \mathrm{L}^{-1}$, at $0.6 \mathrm{MPa}$ pressure, $30{ }^{\circ} \mathrm{C}$ and $3 \mathrm{~L} \mathrm{~min}^{-1}$ flowrate.

Figure 9 shows that the order of the anion effect on spiramycin rejection was $\mathrm{NO}_{3}^{-}>\mathrm{Cl}^{-}>\mathrm{SO}_{4}^{2-}$ for the NF270 membrane. According to the Hofmeister series (Yang 2009), the anionic hydration size order is $\mathrm{SO}_{4}^{2-}>\mathrm{Cl}^{-}>\mathrm{NO}_{3}^{-}$, the Stokes radius of the ions follows the order $r_{\mathrm{S}}\left(\mathrm{SO}_{4}^{2-}\right)>$ $r_{\mathrm{s}}\left(\mathrm{NO}_{3}^{-}\right) \approx \mathrm{Cl}^{-}$. The surface charge density is lower at greater ionic radius, reducing the membrane surface charge effect and abating the streaming effect. Thus, spiramycin rejection was reduced considering the effect of water in the lower spiramycin interception rate and film hole increases in the interception rate role. Therefore, the strength of influence on rejection followed the order $\mathrm{NO}_{3}^{-}>\mathrm{Cl}^{-}>\mathrm{SO}_{4}^{2-}$.

\section{$\overline{\text { CONCLUSIONS }}$}

In this study, spiramycin removal was investigated using four commercial NF membranes (NF270, NF90, ESNA1K1 and ESNA1-LF2-LD). The removal efficiency for spiramycin was influenced by operating pressure, feed temperature, feed concentration, and the presence of cationic and anionic species. The results show that an increase in operating pressure increased the permeate flux and spiramycin rejection. The flux increases almost linearly with increasing temperature, which is consistent with the

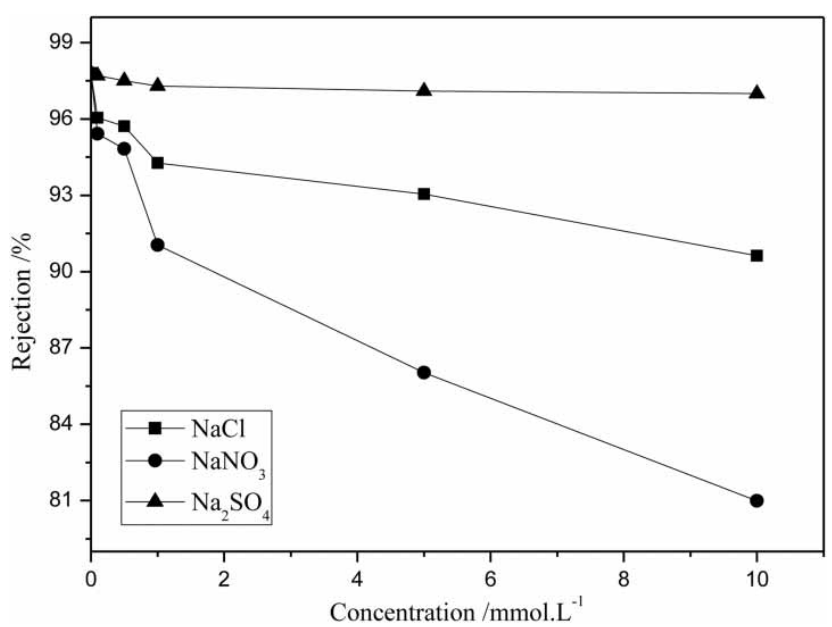

Figure 9 | Effect of concentration and species of anion on spiramycin rejection (NF270 membrane, feed concentration $65 \mathrm{mg} \mathrm{L}^{-1}$; pressure $0.6 \mathrm{MPa}$; feed temperature $30{ }^{\circ} \mathrm{C}$; flowrate $3 \mathrm{~L} \mathrm{~min}{ }^{-1}$ ). 
solution-diffusion model, while the spiramycin rejection decreased with increasing feed temperature. The permeate flux rate declined relatively with increased feed concentration for NF270 and ESNA1-LF2-LD membranes compared with NF90 and ESNA1-K membranes. The presence of cations reduced spiramycin rejection, the greater ionic concentrations causing a larger decrease in rejection. The influence of cations on spiramycin rejection for the NF270 NF membrane followed the sequence $\mathrm{Mg}^{2+}>\mathrm{Ca}^{2+}>\mathrm{K}^{+}$. The presence of anions also resulted in a decrease in spiramycin rejection, with the order being $\mathrm{NO}_{3}^{-}>\mathrm{Cl}^{-}>\mathrm{SO}_{4}^{2-}$ for the NF270 membrane. This study illustrates that NF is a promising technique for the removal of spiramycin from wastewater.

\section{ACKNOWLEDGEMENTS}

The financial support provided the National Natural Science Foundation of China (Nos 21176245, 50978245) and the National Science and Technology Support Program of China (No. 2012BAJ25B02, 2012BAJ25B06) is gratefully acknowledged by the authors.

\section{$\overline{\text { REFERENCES }}$}

Bai, H. 2012 Research of hierarchical simultaneous detection methods and removal efficiency of treatment process for characteristic organic pollutants in antibiotic production Wastewater. Master's Thesis, School of Environmental Science and Engineering, Shandong University, China.

Bai, H., Ben, W. W., Zhou, W. Z. \& Qiang, Z. M. 20I2 Simultaneous determination of spiramycin and neospiramycin in antibiotic production wastewater by ultra performance liquid chromatography-tandem mass spectrometry. J. Instrum. Analysis 31, 90-95.

Batt, A. L., Kim, S. \& Aga, D. S. 2007 Comparison of the occurrence of antibiotics in four full-scale wastewater treatment plants with varying designs and operations. Chemosphere 68, 428-435.

Bhanushali, D., Kloos, S. \& Kurth, C. 200I Performance of solventresistant membranes for non-aqueous systems: solvent permeation results and modeling. J. Membr. Sci. 189, 1-21.

Bouchoux, A., Roux-de Balman, H. \& Lutin, F. 2005 Nanofiltration of glucose and sodium lactate solutions: variation of retention between single- and mixed solutions. J. Membr. Sci. 258, 123-132.

Braeken, L., Bruggen, B. V. D. \& Vandecasteele, C. 2004 Regeneration of brewery waste water using nanofiltration. Water Res. 38, 3075-3082.

China's environmental protection administration 2002 Water and Wastewater Monitoring Analysis Method - 4th edn. China Environmental Science Press, Beijing.
Chon, K., KyongShon, H. \& Cho, J. 2012 Membrane bioreactor and nanofiltration hybrid system for reclamation of municipal wastewater: removal of nutrients, organic matter and micropollutants. Bioresour. Technol. 122, 181-188.

Dolar, D., Vukovic, A., Asperger, D. \& Kosutic, K. 20II Effect of water matrices on removal of veterinary pharmaceuticals by nanofiltration and reverse osmosis membranes. J. Environ. Sci. 23, 1299-1307.

Figoli, A., Cassano, A. \& Criscuoli, A. 20Io Influence of operating parameters on the arsenic removal by nanofiltration. Water Res. 44, 97-104.

Geens, J., Hillen, A. \& Bettens, B. 2005 Solute transport in nonaqueous nanofiltration: effect of membrane material. J. Chem. Technol. Biotechnol. 80, 1371-1377.

Heo, J., Flora, J. R. V., Her, N., Park, Y. G., Cho, J., Son, A. \& Yoon, Y. 2012 Removal of bisphenol A and $17 \beta$-estradiol in single walled carbon nanotubes-ultrafiltration (SWNTs-UF) membrane systems. Sep. Purif. Technol. 90, 39-52.

Homem, V. \& Santos, L. 2oIn Degradation and removal methods of antibiotics from aqueous matrices-a review. J. Environ. Manage. 92, 2304-2347.

Kim, S. D., Cho, J., Kim, I. S., Vanderford, B. J. \& Snyder, S. A. 2007 Occurrence and removal of pharmaceuticals and endocrine disruptors in South Korean surface, drinking, and waste waters. Water Res. 41, 1013-1021.

Kinney, C., Furlong, E. \& Zaugg, S. 2006 Survey of organic wastewater contaminants in biosolids destined for land application. Environ. Sci. Technol. 40, 7207-7215.

Kosutic, K., Dolar, D. \& Asperger, D. 2007 Removal of antibiotics from a model wastewater by RO/NF membranes. Sep. Purif. Technol. 53, 244-249.

Koyuncu, I., Arikan, O. A., Wiesner, M. R. \& Rice, C. 2008 Removal of hormones and antibiotics by nanofiltration membranes. J. Membr. Sci. 309, 94-101.

Kunz, W., Henle, J. \& Ninham, B. W. 2004 'Zur lehre von der wirkung der salze' (about the science of the effect of salts): franz Hofmeister's historical papers. Curr. Opin. Colloid Interf. Sci. 9, 19-37.

Lee, S., Kang, S. I., Lim, J. L., Huh, Y. J., Kim, K. S. \& Cho, J. $20 I I$ Evaluating controllability of pharmaceuticals and metabolites in biologically engineered processes, using corresponding octanol-water distribution coefficient. Ecol. Eng. 37, 1595-1600.

Listiarini, K., Sun, D. D. \& Leckie, J. O. 2009 Organic fouling of nanofiltration membranes: evaluating the effects of humic acid, calcium, alum coagulant and their combinations on the specific cake resistance. J. Membr. Sci. 332, 56-62.

Mo, J. H., Lee, Y. H., Kim, J., Jeong, J. Y. \& Jegal, J. 2008 Treatment of dye aqueous solutions using nanofiltration polyamide composite membranes for the dye wastewater reuse. Dyes Pigm. 76, 429-434.

Nanda, D., Tung, K. L., Hsiung, C. C., Chuang, C. J., Ruaan, R. C., Chiang, Y. C., Chen, C. S. \& Wu, T. H. 2008 Effect of solution chemistry on water softening using charged nanofiltration membranes. Desalination 234, 344-353. 
Park, N. \& Cho, J. 2008 Natural organic matter diffusivity for transport characterizations in nanofiltration and ultrafiltration membranes. J. Membr. Sci. 315, 133-140.

Park, N., Kwon, B., Kim, I. S. \& Cho, J. 2005 Biofouling potential of various NF membranes with respect to bacteria and their soluble microbial products (SMP): characterizations, flux decline, and transport parameters. J. Membr. Sci. 258, 43-54.

Paul, M. A. \& Douglas, R. L. 2000 Anisotropic flat sheet membrane formation via TIPS: thermal effects. J. Membr. Sci. 171, 1-18.

Plakas, K. V. \& Karabelas, A. J. 2008 Membrane retention of herbicides from single and multi-solute media: the effect of ionic environment. J. Membr. Sci. 320, 325-334.

Rams, T. E., Dujardin, S., Sautter, J. D., Degener, J. E. \& Winkelhoff, A. J. V. 20II Spiramycin resistance in human periodontitis microbiota. Anaerobe 17, 201-205.

Rashdi, B. A. M. A., Johnson, D. J. \& Hilal, N. 2013 Removal of heavy metal ions by nanofiltration. Desalination 315, 2-17.

Robinson, J. P., Tarleton, E. S. \& Millington, C. R. 2004 Solvent flux through dense polymeric nanofiltration membranes. J. Membr. Sci. 230, 29-37.

Shi, D. Q., Kong, Y. \& Yu, J. X. 2006 Separation performance of polyimide nanofiltration membranes for concentrating spiramycin extract. Desalination 191, 309-317.

Shirra, G. R., Ifat, K. M., Lilly, H. G., Ofir, R. \& Carlos, G. D. 20 II Influence of seasonal and operating conditions on the rejection of pharmaceutical active compounds by RO and NF membranes. Desalination 277, 250-256.
Sorensen, B. H. 2000 Algal toxicity of antibacterial agents used in intensive farming. Chemosphere 40, 731-739.

Sorin, A., Reguillon, A. F., Rostaing, S. P., Sbai, M., Szymczyk, A., Fievet, P. \& Lemaire, M. 2005 Rejection of Gd(III) by nanofiltration assisted by complexation on charged organic membrane: influences of $\mathrm{pH}$, pressure, flux, ionic strength and temperature. J. Membr. Sci. 267, 41-49.

Sun, S. P., Hatton, T. A. \& Chung, T. S. 2om Hyperbranched polyethyleneimine induced cross-linkin gof polyamide-imide nanofiltration hollow fiber membranes for effective removal of ciprofloxacin. Environ. Sci. Technol. 45, 4003-4009.

$\mathrm{Xu}, \mathrm{L}$., Du, L. S. \& Wang, C. 2012 Nanofiltration coupled with electrolytic oxidation in treating simulated dye wastewater. J. Membr. Sci. 409-410, 329-334.

Yang, Z. 2009 Hofmeister effects: an explanation for the impact of ionic liquids on biocatalysis. J. Biotechnol. 144, 12-22.

Yu, Y., Zhao, C. W., Wang, Y. G., Fan, W. H. \& Luan, Z. K. 2013 Effect of ion concentration and natural organic matter on arsenic (V) removal by nanofiltration under different transmembrane pressures. J. Environ. Sci. 25, 302-307.

Zazouli, M. A., Susanto, H., Nasseri, S. \& Ulbricht, M. 2009 Influences of solution chemistry and polymeric natural organic matter on the removal of aquatic pharmaceutical residuals by nanofiltration. Water Res. 43, 3270-3280.

Zhang, W., He, G. H. \& Gao, P. 2003 Development and characterization of composite nanofiltration membranes and their application in concentration of antibiotics. Sep. Purif. Technol. 30, 27-35.

First received 10 December 2012; accepted in revised form 24 May 2013 